\title{
FORMULATION AND EVALUATION OF METRONIDAZOLE BIOADHESIVE MATRICES FOR TREATMENT OF PERIODONTITIS
}

\author{
E. Ramadan ${ }^{1 *}$, Th. Borg ${ }^{1}$, Y.M. El Hawary ${ }^{2}$ and N. M. Saleh ${ }^{1}$ \\ ${ }^{1}$ Department of Pharmaceutics, Faculty of Pharmacy, ${ }^{2}$ Department of Oral Biology, Faculty of \\ Dentistry, Mansoura University, Mansoura, Egypt
}

\begin{abstract}
تناول هذا البحث تحضير عقار مترونيدازول في صورة هلاميات ورقائق لها خاصية الالتصاق

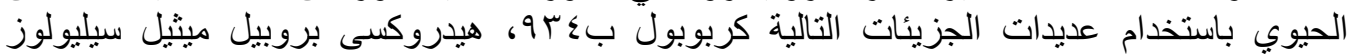

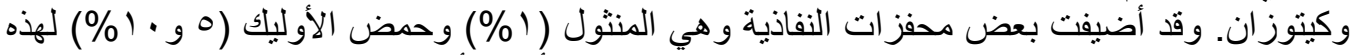

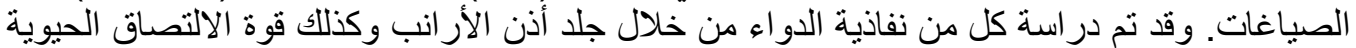

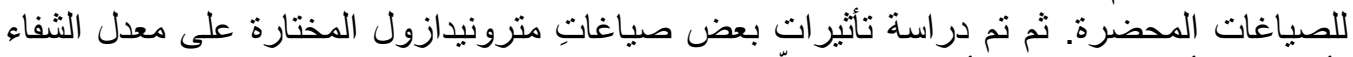

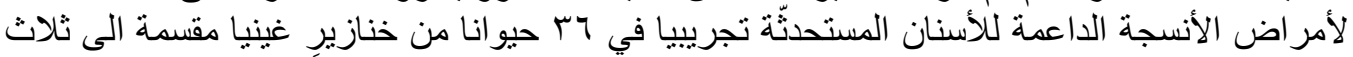

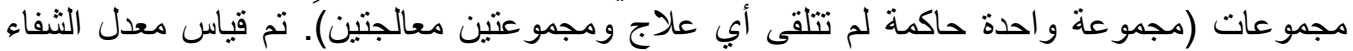
بطريقة تشريحية وكذللك باستخدام نظام العلامات.

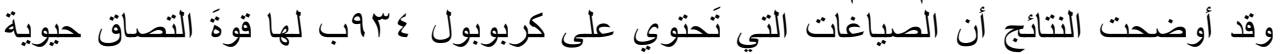

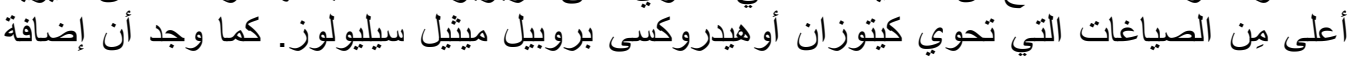

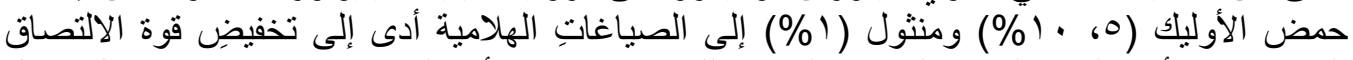

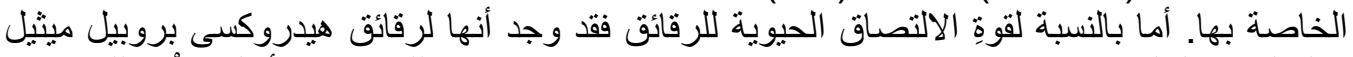

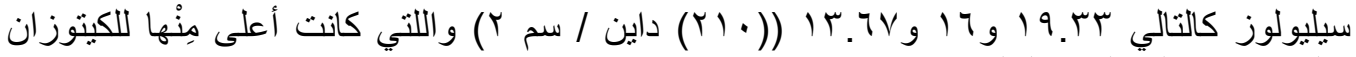

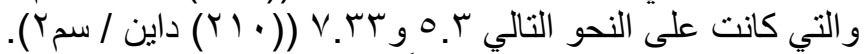

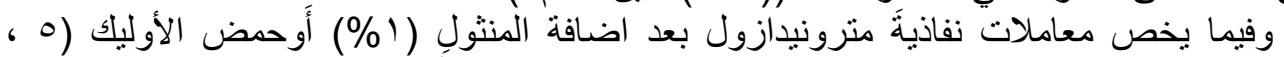

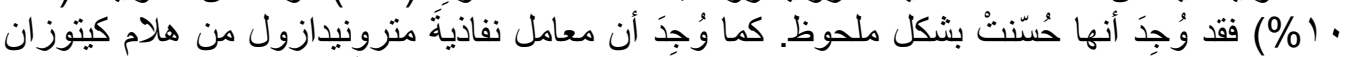

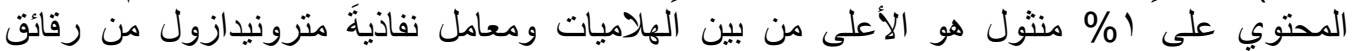

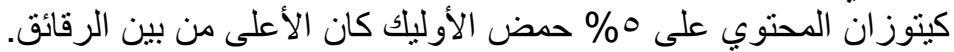

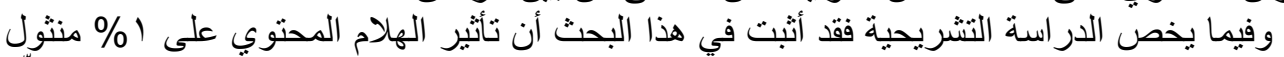

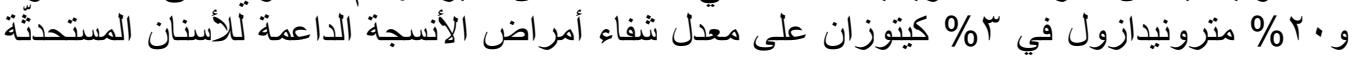

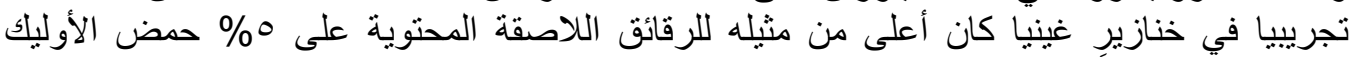

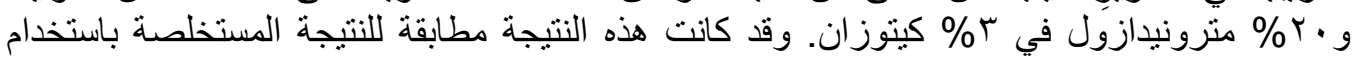
نظام العلامات.
\end{abstract}

Metronidazole (Mz) (an anaerobic antibacterial agent) was incorporated into different bioadhesive matrices including gels and films using carbopol 934p (4\%), chitosan (3\%) and hydroxypropyl methyl cellulose (HPMC) (3\%). Penetration enhancers including menthol (1\%) or oleic acid (OA) (5\%, 10\%) were incorporated in such formulations. The bioadhesive forces of the prepared matrices were determined and expressed as detachment stresses (Dyne/ $\left.\mathrm{cm}^{2}\right)$. Permeability of $\mathrm{Mz}$ across ear rabbit skin and enhancement ratios (ER) were studied. The effects of selected $\mathrm{Mz}$ formulations on the healing rate of experimentally induced periodontitis in guinea pigs were estimated and histologically compared between treated and control groups.

The obtained results showed that the gel formulations containing carbopol 934p exhibited maximum bioadhesive force with detachment stress equals to $66.98 \times 10^{2}$ dyne/ $\mathrm{cm}^{2}$ followed by those containing chitosan $\left(42.45 \times 10^{2}\right.$ dyne/cm $\left.{ }^{2}\right)$ and HPMC $\left(26.41 \times 10^{2}\right.$ dyne/ $\left.\mathrm{cm}^{2}\right)$. There was a statistically significant difference $(P<0.05)$ between the detachment stresses of gel formulations containing penetration enhancers and the corresponding ones without penetration enhancer. HPMC based films had bioadhesive force $\left(19.33,16\right.$ and $13.67 \times 10^{2}$ dyne/cm $\left.{ }^{2}\right)$ higher than those based on chitosan (5.33 and $7.33 \times 10^{2}$ dyne/ $\left.\mathrm{cm}^{2}\right)$.

Also, it was noticed that the chitosan gel containing $1 \%$ menthol had the highest ER (5.13) among other gel formulations. On the other hand, chitosan based film containing 5\% OA has the highest ER (1.73) among films. The effects of the selected formulations on the healing 
periodontal wound showed that bioadhesive chitosan gel containing menthol had accelerated the periodontal wound healing more than chitosan based film containing oleic acid.

\section{INTRODUCTION}

Periodontal diseases are conditions including gingivitis and periodontitis that affect the supporting structures of the teeth ${ }^{1}$. They are accompanied with initial extension to and accumulation of plaque at the gingival margin that, in turn, induces an inflammatory response $^{2}$. Moreover, direct actions of both plaque and the induced inflammatory response within the deeper tissues, a space (pocket) develops between the roots of the affected teeth and the soft tissues ${ }^{3}$. Hence, these environments are good for bacterial accumulation and flourishing. If the disease is allowed to progress, increased tooth mobility and ultimately tooth loss may result ${ }^{4}$.

The microbiological treatment of periodontitis is through either the use of systemic antibiotics 5 or a localized delivery system incorporating an antibiotic. In the systemic use, large doses must be taken in order to achieve sufficient concentrations in the gingival crevicular fluid of the periodontal pocket ${ }^{6}$. Such administration may not produce an adequate concentration at the action site as well as the problems associated with the side effects of high doses of an antibiotic.

Alternatively to compensate such problems the local administration of the drug in a controlled release delivery system is selection of research. Appropriate materials for bioadhesion are mainly hydrogel-forming polymers may be used for such hypothesis.

$\mathrm{Mz}$ is a front-line chemotherapeutic agent for treating infections by anaerobic bacteria such as Porphyromonas gingivalis because of the low minimum inhibitory concentration (MIC) required ${ }^{7}$. Such drug has to be formulated in mucoadhesive polymers to be delivered via transmucosal route. The primary disadvantage associated with oral transmucosal delivery route is the low flux ${ }^{8}$. So that, the effects of various penetration enhancers on such delivery had been studied to improve the absorption pattern of the drug molecules.

Hence, the aim of this study is the preparation and evaluation of the prepared bioadhesive matrices containing metronidazole as localized systems for periodontitis treatment to minimize the side effects emerged of systemic one. Meanwhile, the study of the effects of some penetration enhancers on the drug delivery was of prime interest. The study also has extended to evaluate the histological effects of the prepared formulations on periodontitis induced in guinea pigs.

\section{EXPERIMENTAL}

\section{Materials}

Metronidazole (Mz) was kindly supplied by Memphis pharmaceutical Co., Cairo, Egypt, Hydroxypropyl methyl cellulose (HPMC) (Methocel K100 M) (Dow Chem. Co., Midland MI, USA), Carbopol 934P (USP $400 \mathrm{cps}$ BDH, Ltd, England), Menthol (Sigma chemical Co., St. Louis, Mo., USA), Chitosan $<80$ mesh (Bioshell, USA), All other chemicals were of analytical grade.

\section{Equipment}

UV Spectorophotometer (Shimadzu, UV150-02, Sersakusho, Ltd, Kyoto, Japan), pH meter (Beckman Instrumentals fullerton, CA 92634), Rotary viscometer (Roto Visco, Germany), Thermostatically controlled shaking water bath (Grant instrument Cambridge Ltd., Barrington Cambridge B2, 5002, England), Magnetic stirrers (Heidolph, U.S.A.), Light microscope (Nikon, Japan), Digital camera (3x optical zoom, $4 \times$ digital zoom, Olympus Camedia D-540 Zoom, Olympus, Japan).

\section{Methodology}

\section{Preparation of Mz Bioadhesive Matrices}

A- Preparation of bioadhesive gel formulations

The ingredients of the prepared $\mathrm{Mz}$ gel formulations are shown in Table (1). HPMC and carbopol 934P bioadhesive gel formulations were prepared by the method stated by Rowe et al. ${ }^{9}$. On the other hand, chitosan gel formulations were prepared using $1 \%$ lactic acid instead of distilled water method stated by Senel et al. ${ }^{10}$. The dispersions were set a side overnight to form a gel. The drug was added after mixing with a part of vehicle to the

Table 1: Composition of the prepared bioadhesive formulations. 


\begin{tabular}{|c|c|c|c|c|c|c|c|c|c|c|c|c|}
\hline \multirow{2}{*}{ Ingredients } & \multicolumn{12}{|c|}{ Concentration $(\% \mathrm{w} / \mathrm{w})$} \\
\hline & \multicolumn{9}{|c|}{ Bioadhesive gels } & \multicolumn{3}{|c|}{ Bioadhesive films } \\
\hline Formula & $\overline{F_{1}}$ & $\mathrm{~F}_{2}$ & $\mathrm{~F}_{3}$ & $\overline{F_{4}}$ & $\overline{F_{5}}$ & $\mathrm{~F}_{6}$ & $\mathrm{~F}_{7}$ & $\overline{F_{8}}$ & $\overline{\mathrm{F}_{9}}$ & $\overline{F_{10}}$ & $\mathrm{~F}_{11}$ & $\mathrm{~F}_{12}$ \\
\hline $\mathrm{Mz}$ & 20 & 20 & 20 & 20 & 20 & 20 & 20 & 20 & 20 & 20 & 20 & 20 \\
\hline Chitosan & 3 & 3 & 3 & - & - & - & - & - & - & 3 & - & - \\
\hline Carbopol 934p & - & - & - & 4 & 4 & 4 & - & - & - & - & - & - \\
\hline HPMC & - & - & - & - & - & - & 3 & 3 & 3 & - & 3 & 3 \\
\hline $\mathrm{OA}$ & 5 & 10 & - & 5 & 10 & - & 5 & 10 & - & 5 & - & 5 \\
\hline Menthol & - & - & 1 & - & - & 1 & - & - & 1 & - & 1 & - \\
\hline Ethanol & - & - & 20 & - & - & 20 & - & - & 20 & - & - & - \\
\hline Glycerol & - & - & - & - & - & - & - & - & - & 10 & 10 & 10 \\
\hline TEA** & \multicolumn{12}{|c|}{2.5} \\
\hline Solvent* to & & & & & & & 00 & & & & & \\
\hline
\end{tabular}

* solvent is distilled water for all formulations except for chitosan ones solvents are $1 \%$ lactic acid and $1.5 \%$ acetic acid for bioadhesive gels and films respectively.

**TEA was added to adjust $\mathrm{pH}$ to 6.8 .

formed gel. In case of incorporating OA to the gel formulations, it was emulsified with Tween 80 to form emulsion gel (emulgel) ${ }^{11}$. While in ethanol $(20 \%)$ was used to solubilize menthol. The total weight was adjusted to 100 gram with vehicle. Control formulations $\left(\mathrm{F}_{\text {con1 } 1}, \mathrm{~F}_{\mathrm{con} 2}, \mathrm{~F}_{\mathrm{con} 3}\right)$ were prepared of chitosan, HPMC and carpobol respectively containing the same components without penetration enhancers.

\section{B- Preparation of bioadhesive films}

Table (1) shows the ingredients of bioadhesive films expressed as percent of total weight. Bioadhesive films with or without enhancers were prepared by a solvent casting method $^{12}$. Glycerin was added in concentration of $10 \%$ as plasticizer. $\mathrm{Mz}$ was incorporated into the formed gel after mixing with a part of vehicle. The total weight was adjusted to 100 gm with the vehicle.

The resultant medicated gels were left over night to allow deaeration. Thirty grams of each gel were casted into glass petri dishes $\left(70.88 \mathrm{~cm}^{2}\right)$ so that $0.42 \mathrm{~g} / 1 \mathrm{~cm}^{2}$ were dried in a levelled oven maintained at $40^{\circ} \mathrm{C}$ until flexible film formed. The film was cut into smaller discs each one equivalent to $0.1 \mathrm{~g} \mathrm{Mz}$ packed in aluminium foil and stored in glass containers maintained at room temperature. Control formulations $\left(\mathrm{F}_{\text {con4 }}, \mathrm{F}_{\text {con5 }}\right)$ were prepared of chitosan and HPMC respectively containing the same components without penetration enhancers.

\section{Evaluation of bioadhesive forces}

The bioadhesion strengths of the prepared formulations were determined by measuring the force required to detach the formulations from mucous membrane (rabbit intestine) using device in Figure $(1)^{13}$.

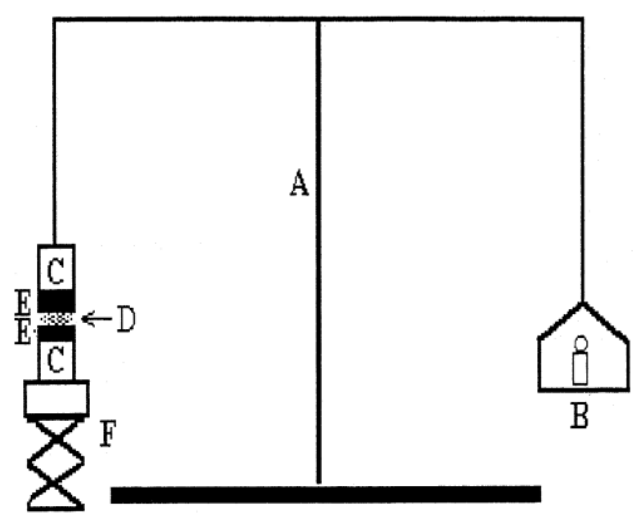

Fig 1: Bioadhesive force-measuring device, (A) modified balance; (B) weights; (C) glass vial; (D) The bioadhesive tablet; (E) rabbit intestine; (F) height-adjustable pan.

The minimal weight to detach gel from mucosal tissue was noted as the bioadhesive force. All detachment tests were carried out in air. The mucoadhesive force or detachment stress $\left(\right.$ Dyne $/ \mathrm{cm}^{2}$ ) was determined using the equation stated by Ch'ng et al. ${ }^{14}$

$$
\text { Detachment stress }=\mathrm{m} . \mathrm{g} / \mathrm{A}
$$

Where $\mathrm{m}$ is the minimal weight $(\mathrm{gm}), \mathrm{g}$ is the acceleration due to gravity taken as $9.81 \mathrm{~m} / \mathrm{sec}^{2}$ and $\mathrm{A}$ is the area of the mucosal tissue (area of 
contact) and is equal to $\pi \cdot r^{2}$ ( $r$ is the radius of the glass vial).

\section{In-vitro permeation across rabbit ear skin A- Isolation of rabbit ear skin}

Rabbit skin was excised post-sacrifice from the inner part of rabbit ear (6 months old) obtained from a local slaughters house, the hair was removed by hand and the skin cleaned with saline solution $(0.9 \% \mathrm{w} / \mathrm{v})$. After that, the skin was refrigerated $\left(2-5^{\circ} \mathrm{C}\right)$ and used within three days ${ }^{15}$.

\section{B- Permeation experiments}

Permeation experiments were conducted in modified Franz-type diffusion cell with an exposed surface of $9.62 \mathrm{~cm}^{2}$. The rabbit ear skin was mounted on the mouth of donor halfcell and the later was positioned in the middle of $250 \mathrm{ml}$ beaker serving as receptor compartment. The permeability experiments were conducted with $100 \mathrm{ml}$ of phosphate buffer $\mathrm{pH} 6.8$ in the receiver chamber and 0.5 gram of gel in the donor chamber at $37^{\circ} \mathrm{C} \pm 0.2$.

\section{C- Permeation parameters}

The total permeability coefficient $(P)$ is calculated at steady state under sink conditions. Experiment was run long enough so that the steady state portions are 3 to 5 times larger than lag times. The method reported by Yoneto et $a l .{ }^{16}$ was used to analyze permeation data and determine permeability coefficients through rabbit ear skin which used as permeation barrier. The permeability coefficients $(P)$ were calculated according to the following equation and were expressed by $\left(\mathrm{gm} / \mathrm{cm}^{2} . \mathrm{hr}\right)$ :

Where:

$$
P=(\mathrm{dQ} / \mathrm{dt}) / \mathrm{A} . \mathrm{C}
$$

A: The diffusion area $\left(7.07 \mathrm{~cm}^{2}\right)$

$\mathrm{dQ} / \mathrm{dt}$ : The slope of the linear region for the plot of $\mathrm{Mz}$ amount in the receiver chamber versus time.

C: The donor concentration

The permeation enhancing activities were expressed as enhancement ratios (ER) of permeability ${ }^{17}$ :

$\mathrm{ER}=\frac{\text { Dug permeability with penetration enhancer }}{\text { Drug permeability without penetration enhancer }}$

\section{Surface pH and swelling study of muco- adhesive films}

The surface $\mathrm{pH}$ of the prepared films were determined using the method described by Nafee et al. ${ }^{18}$ in which films were left to swell for $2 \mathrm{hrs}$ on the surface of an agar plate prepared by dissolving $2 \%$ agar in warmed isotonic phosphate buffer of $\mathrm{pH} 6.8$ under stirring and then pouring the solution into a Petri dish till gelling at room temperature. The surface $\mathrm{pH}$ was measured by means of a $\mathrm{pH}$ meter which placed onto the surface of the swollen films and allowing it to equilibrate for 1 min prior to recording the readings. A mean of three readings was recorded.

Swelling study was conducted by the method described by Nafee et al. ${ }^{18}$. After determination of the original film diameter $\left(X_{o}\right)$, the samples were allowed to swell on the surface of agar plate kept in an incubator maintained at $37^{\circ} \mathrm{C}$. The diameter of the swollen film $\left(\mathrm{X}_{\mathrm{t}}\right)$ after time $(\mathrm{t})$ was determined at preset time intervals 1, 2, 3, 4 and $5 \mathrm{hr}$. The percent swelling, $(\% \mathrm{~S})$ was calculated using the following equation:

Where:

$$
\% \mathrm{~S}=\mathrm{X}_{\mathrm{t}}-\mathrm{X}_{\mathrm{o}} / \mathrm{X}_{\mathrm{o}} \times 100
$$

$\mathrm{X}_{\mathrm{t}}$ : The diameter of the swollen film after time

$X_{0}$ : The original film diameter at zero time.

Evaluation of the effects of Mz formulations on the healing of experimentally induced periodontitis in guinea pigs

Forty eight animals were classified into three groups (one control and two treated) each one containing sixteen animals. Each group was subdivided into three subgroups, four animals each, representing the healing at three time points ( 3 days, 15 days and one month).

\section{A- Induction of periodontitis}

Periodontal disease (periodontitis) was induced in all animals (36 guinea pigs) by ligation method ${ }^{19}$. This was accomplished by placing a 3-0 sterilized silk suture around the mandibular incisors. The ligature was knotted on the buccal side of the tooth, resulting in a subgingival position lingually and in supragingival position buccally. Ligatures were left in place for two weeks. At the end of this period the clinical manifestations of 
periodontitis was observed including tooth mobilization, flushing and redness of gingiva, bleeding upon probing and formation of periodontal pocket. After that the ligatures were removed and application was started for treated groups not for control group.

\section{B- Application}

After removal of ligatures, the daily treatment was started. Each animal of treated groups was firstly anesthetized by inhalation of few drops of diethyl ether and after that $0.25 \mathrm{~g}$ of mucoadhesive formulations, which were equivalent to $58.13 \mathrm{mg} / \mathrm{kg} \mathrm{Mz}$ per day (the calculated dose of metronidazol in guinea pigs), was applied. The gel was applied according to the method reported by Reis de Vasconcellos et $a .^{20}{ }^{20}$ in which the gel was injected using a syringe into periodontal pocket. On the other hand, the bioadhesive film equivalent to the calculated dose of metronidazol in guinea pigs was fixed on the gingiva by applying pressure using finger for 5 min. The application was repeated once daily for each animal of treated groups until time of sacrification by decapitation under etherinduced anaesthesia.

\section{C- Histological examination}

After animals sacrifice, the anterior part of the mandible of each animal were taken and prepared for haematoxylin and eosin (H\&E) stain using a technique reported by Druy \& Wallington $^{21}$ and known as the paraffin technique.

The slides regarding all animals' tissues were inspected under light microscope. After that, photomicrographic pictures of the slides which clearly showing our findings were captured using the digital camera mounted on the eyepiece of the microscope.

To compare the efficacy of formulations and to optimize the method for evaluation, a subjective score was utilized to assess the degree of healing. Five grades of healing were recorded for each of the following: gingival tissues, fibers of periodontal ligament and alveolar bone by observing reduction of granulation tissue, detachment of the periodontal ligament and resorption of bone. The five grades were minimal (0), mild $(+)$, moderate $(++)$, improved but incomplete $(+++)$ and nearly complete healing $(++++)$.

\section{RESULTS AND DISCUSSION}

\section{Determination of bioadhesive forces \\ 1. Bioadhesive gel formulations}

The detachment stresses of gel formulations were $42.45,66.98$ and $26.41 \times 10^{2}$ dyne $/ \mathrm{cm}^{2}$ for $\mathrm{F}_{\text {con1 }}, \mathrm{F}_{\mathrm{con} 2}$ and $\mathrm{F}_{\text {con3 } 3}$ respectively (Table 2). It was observed that the incorporation of OA $(5 \% \& 10 \%)$ resulted in reducing detachment stresses of $F_{\text {con1 } 1}$ to 26.41 and $30.09 \times 10^{2}$ dyne $/ \mathrm{cm}^{2}$ for $\mathrm{F}_{1}$ and $\mathrm{F}_{2}$ respectively. The same findings were obtained upon using carbopol 934p and HPMC as matrices for formulations.

Table 2: Detachment stresses of $\mathrm{Mz}$ bioadhesive formulations.

\begin{tabular}{|c|c|c|}
\hline \multicolumn{2}{|c|}{$\begin{array}{c}\begin{array}{c}\text { Formulation } \\
\text { Code }\end{array} \\
\end{array}$} & $\begin{array}{c}\text { *Detachment stress } \times 10^{2} \\
\left(\text { dyne } / \mathrm{cm}^{2}\right)\end{array}$ \\
\hline \multirow{4}{*}{ 总 } & $\mathrm{F}_{\text {con } 1}$ & $42.45 \pm 0.74$ \\
\hline & $\mathrm{F}_{1}$ & $26.41 \pm 0.32$ \\
\hline & $\mathrm{F}_{2}$ & $30.09 \pm 0.66$ \\
\hline & $\mathrm{F}_{3}$ & $35.85 \pm 0.89$ \\
\hline \multirow{4}{*}{ 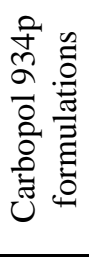 } & $\mathrm{F}_{\text {con2 }}$ & $66.98 \pm 0.54$ \\
\hline & $\mathrm{F}_{4}$ & $41.51 \pm 1.53$ \\
\hline & $\mathrm{F}_{5}$ & $30.19 \pm 1.63$ \\
\hline & $\mathrm{F}_{6}$ & $52.83 \pm 1.63$ \\
\hline \multirow{4}{*}{ 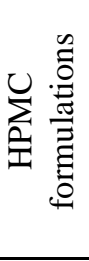 } & $\mathrm{F}_{\text {con3 }}$ & $26.41 \pm 1.63$ \\
\hline & $\mathrm{F}_{7}$ & $21.70 \pm 0.89$ \\
\hline & $\mathrm{F}_{8}$ & $16.98 \pm 0.00$ \\
\hline & $\mathrm{F}_{9}$ & $18.87 \pm 1.63$ \\
\hline \multirow{5}{*}{ 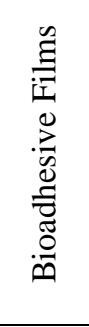 } & $\mathrm{F}_{\text {con4 }}$ & $5.33 \pm 0.028$ \\
\hline & $\mathrm{F}_{10}$ & $7.33 \pm 0.016$ \\
\hline & $\mathrm{F}_{\text {con } 5}$ & $19.33 \pm 0.51$ \\
\hline & $\mathrm{F}_{11}$ & $16.00 \pm 0.09$ \\
\hline & $\mathrm{F}_{12}$ & $13.67 \pm 0.51$ \\
\hline
\end{tabular}

*Mean of three determinations \pm SD.

After incorporation of OA (5\% and 10\%) the detachment stresses became 41.51 and $30.19 \times 10^{2}$ dyne $/ \mathrm{cm}^{2}$ for $F_{4}$ and $F_{5}$ and 21.7 and 
$16.98 \times 10^{2}$ dyne $/ \mathrm{cm}^{2}$ for $\mathrm{F}_{7}$ and $\mathrm{F}_{8}$ respectively. In addition, it was found that the incorporation of menthol $(1 \%)$ to the gel formulations reduced their detachment stresses to 35.85 , 52.83 and $18.87 \times 10^{2}$ dyne $/ \mathrm{cm}^{2}$ for $\mathrm{F}_{3}, \mathrm{~F}_{6}$ and $\mathrm{F}_{9}$ respectively.

Statistical analysis using student t-test revealed that there is a statistically significant difference $(\mathrm{P}<0.05)$ between the detachment stresses of gel formulations containing penetration enhancers and the corresponding ones without penetration enhancer. The observed decrease in detachment stresses of gel formulations which associate the incorporation of menthol or OA may be attributed to reduction in the hydration of bioadhesive polymer. The adhesion of materials with mucosae is the result of the following steps: polymer hydration, wetting of mucosa, diffusion into mucus and chemical bonding with the glycoproteins ${ }^{22}$. It was reported that polymer hydration is very important to enhance the interpenetration process between polymer and $\operatorname{mucin}^{23}$.

The results of polymeric bioadhesion revealed that the formulations containing carbopol $934 p$ (anionic polymer) exhibited maximum bioadhesive force followed by those containing chitosan (cationic) and HPMC (nonionic) (Table 2). These finding was in agreement with those reported by Peppas and Buri $^{24}$ who found that strong anionic charge on the polymer is one of the required characteristics for mucoadhesion where nonionic polymers appear to undergo a smaller degree of adhesion compared to anionic polymers.

In addition, polyacrylic acids have excellent mucoadhesive properties, probably due to hydrogen bond formation with the functional groups of mucus ${ }^{25}$. Moreover, it was reported that some cationic high molecular weight polymers, such as chitosan, have shown to possess good adhesive properties ${ }^{26}$. An invitro method for buccal adhesion study reported that carbopol formulations have the highest values of bioadhesion, followed by hydroxypropylmethyl cellulose (HPMC) and on the other hand, chitosan appeared to have low bioadhesive values ${ }^{27}$.

\section{Mz bioadhesive films}

Table (2) shows the detachment stresses of the prepared $\mathrm{Mz}$ bioadhesive formulations. It was found that the detachment stresses of chitosan films were 5.33 and $7.33 \times 10^{2}$ dyne $/ \mathrm{cm}^{2}$ for $\mathrm{F}_{\text {com4 }}$ and $\mathrm{F}_{10}$ respectively. For HPMC films the detachment stresses of $F_{\text {com5 }}$, $F_{11}$ and $F_{12}$ were $19.33,16$ and $13.67 \times 10^{2}$ dyne $/ \mathrm{cm}^{2}$ respectively. It was concluded that HPMC based films have bioadhesive force higher than those based on chitosan. But for both the bioadhesive forces of the prepared films were relatively smaller than those of bioadhesive gels. It may be attributed to that all films contain water content less than that of bioadhesive gels.

The hydration is required for a mucoadhesive polymer to expand and to induce mobility in the polymer chains in order to enhance the interpenetration process between polymer and $\operatorname{mucin}^{23}$. Therefore polymer swelling in turn would be relatively small and interaction between the polymer and the mucous network reduced resulting in decrease in bioadhesive force. The threshold of the bioadhesive force for keeping the attachment onto the human oral mucosa for $4 \mathrm{hrs}$ is 4.50 dyne $/ \mathrm{cm}^{228}$. So that, it was concluded that all the formulations could be attached for at least 4 hrs.

\section{Permeation studies}

\section{Mz bioadhesive gel formulations}

Release profiles of $\mathrm{Mz}$ from chitosan, carbopol 934p and HPMC gel formulations containing menthol or $\mathrm{OA}$ are illustrated in Figures (2-4) respectively. For chitosan gel formulations, it was found that the percent $\mathrm{Mz}$ released from $\mathrm{F}_{\text {con1 }}$ was raised from 2.6 to 5.64, 7.6 and $11.067 \%$ for formulations $F_{1}, F_{2}$ and $F_{3}$ respectively. The release profile of $\mathrm{Mz}$ from carbopol 934p gels showed that $\mathrm{Mz}$ released from $\mathrm{F}_{\text {con3 }}$ was raised from 5 to $9.63,12.917$ and $6.537 \%$ for formulations $F_{6}, F_{4}$ and $F_{5}$ respectively. Also it was observed that the percent $\mathrm{Mz}$ released from HPMC gel $\mathrm{F}_{\text {con2 }}$ raised from 9.11 to $10.3,18.507$ and $10.61 \%$ for formulations $F_{9}, F_{7}$ and $F_{8}$ respectively. On the other hand, Lag time wasn't exhibited by any one of the prepared formulations. 


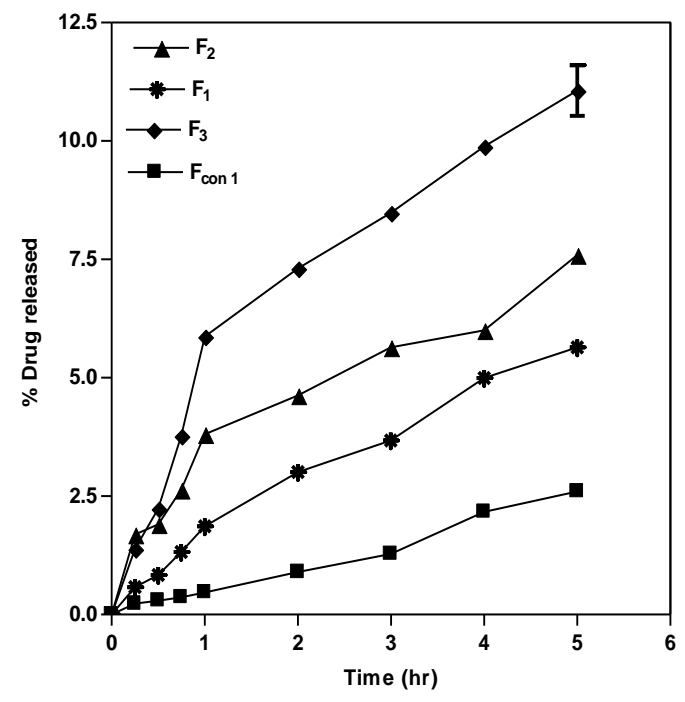

Fig. 2: Release profiles of $\mathrm{Mz}$ from chitosan gel formulations containing menthol or OA.

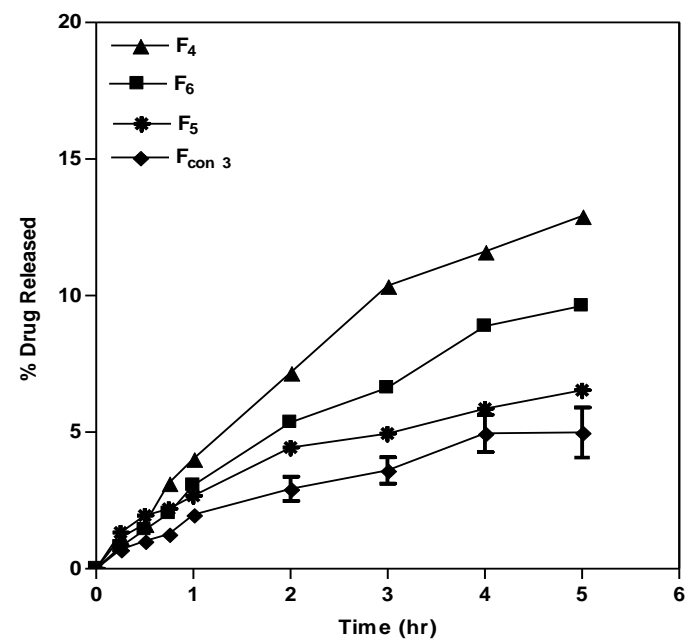

Fig. 3: Release profiles of Mz from carbopol $934 \mathrm{p}$ gel formulations containing menthol or OA.

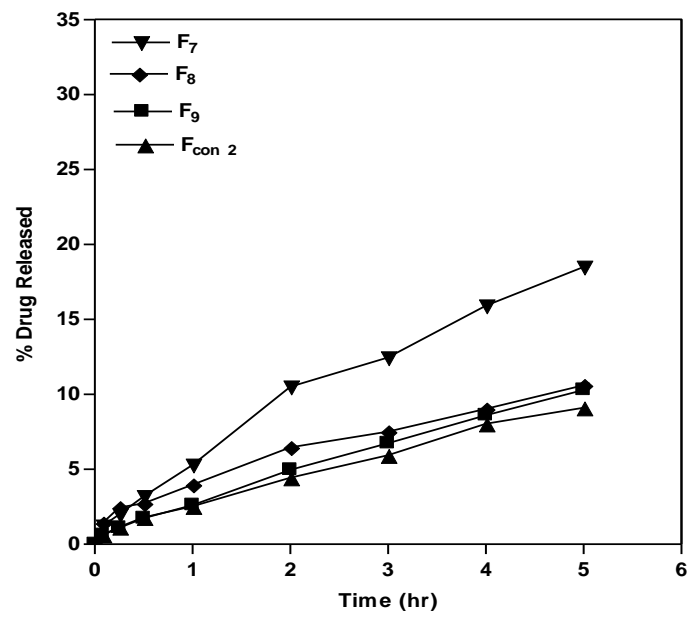

Fig. 4: Release profiles of $\mathrm{Mz}$ from HPMC gel formulations containing menthol or OA.
Table (3) shows the permeability coefficients and enhancement ratios of the prepared $\mathrm{Mz}$ formulations. It was observed that the permeability coefficients of chitosan gel formulations were $0.72,1.2,0.96$ and 3.69 $\left(\times 10^{-3} \mathrm{~g} / \mathrm{cm}^{2} . \mathrm{hr}\right)$ for $\mathrm{F}_{\text {con } 1}, \mathrm{~F}_{1}, \mathrm{~F}_{2}$ and $\mathrm{F}_{3}$ respectively. The permeability coefficients of HPMC gel formulations were 1.26, 2.7, 1.44 and $1.45\left(\times 10^{-3} \mathrm{~g} / \mathrm{cm}^{2} . h r\right)$ for $\mathrm{F}_{\text {com3 }}, \mathrm{F}_{7}, \mathrm{~F}_{8}$ and $\mathrm{F}_{9}$ respectively. So that, it was revealed that the permeability of the drug after incorporation of menthol $(1 \%)$ or OA $(5,10 \%)$ was enhanced significantly $(\mathrm{P}<0.05)$ for all polymers used.

Table 3: Permeability coefficients and enhancement ratios of the prepared $\mathrm{Mz}$ formulations.

\begin{tabular}{|c|c|c|c|c|}
\hline \multicolumn{2}{|c|}{$\begin{array}{l}\text { Formula } \\
\text { Code }\end{array}$} & $\begin{array}{c}\text { Enhancer } \\
(\% \mathrm{w} / \mathrm{w})\end{array}$ & $\begin{array}{l}* P \times 10^{-3} \\
\left(\mathrm{~g} / \mathrm{cm}^{2} \cdot \mathrm{hr}\right)\end{array}$ & (ER) \\
\hline \multirow{4}{*}{ 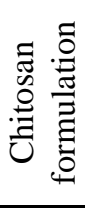 } & $F_{\text {con1 }}$ & - & $0.72 \pm 0.02$ & - \\
\hline & $F_{1}$ & $\mathrm{OA}(5)$ & $1.20 \pm 0.03$ & 1.67 \\
\hline & $\mathrm{F}_{2}$ & $\mathrm{OA}(10)$ & $0.96 \pm 0.05$ & 1.33 \\
\hline & $\mathrm{F}_{3}$ & Menthol(1) & $3.69 \pm 0.04$ & 5.13 \\
\hline \multirow{4}{*}{ 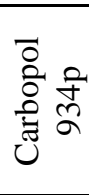 } & $\mathrm{F}_{\text {con2 }}$ & - & $0.66 \pm 0.01$ & 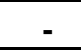 \\
\hline & $\mathrm{F}_{4}$ & $\mathrm{OA}(5)$ & $1.92 \pm 0.02$ & 2.9 \\
\hline & $\mathrm{F}_{5}$ & $\mathrm{OA}(10)$ & $0.84 \pm 0.02$ & 1.27 \\
\hline & $\mathrm{F}_{6}$ & Menthol(1) & $1.32 \pm 0.03$ & 2 \\
\hline \multirow{4}{*}{ 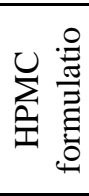 } & $\mathrm{F}_{\text {con3 }}$ & - & $1.26 \pm 0.03$ & - \\
\hline & $\mathrm{F}_{7}$ & $\mathrm{OA}(5)$ & $2.70 \pm 0.02$ & 2.14 \\
\hline & $\mathrm{F}_{8}$ & $\mathrm{OA}(10)$ & $1.44 \pm 0.06$ & 1.14 \\
\hline & $\mathrm{F}_{9}$ & Menthol(1) & $1.45 \pm 0.01$ & 1.15 \\
\hline \multirow{5}{*}{ 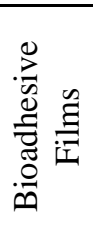 } & $\mathrm{F}_{\text {con } 4}$ & - & $0.36 \pm 0.01$ & - \\
\hline & $\mathrm{F}_{10}$ & $\mathrm{OA}(5)$ & $0.54 \pm 0.01$ & 1.73 \\
\hline & $\mathrm{F}_{\text {con5 }}$ & - & $1.56 \pm 0.02$ & - \\
\hline & $\mathrm{F}_{11}$ & Menthol(1) & $1.08 \pm 0.04$ & 0.821 \\
\hline & $F_{12}$ & $\mathrm{OA}(5)$ & $0.72 \pm 0.01$ & 0.457 \\
\hline
\end{tabular}

*Mean of three determinations \pm SD.

Also it was found for each polymer formulations that the permeability coefficients of the formulations containing $10 \% \mathrm{OA}\left(\mathrm{F}_{2}, \mathrm{~F}_{5}\right.$ and $\mathrm{F}_{8}$ ) were less than that of the corresponding formulations containing 5\% OA $\left(\mathrm{F}_{1}, \mathrm{~F}_{4}\right.$ and $\left.\mathrm{F}_{7}\right)$. So that it was revealed that increase $\mathrm{OA}$ concentration wasn't accompanied with increase in permeability.

This finding is in agreement with this reported by Mortazavi and Aboofazeli ${ }^{29}$ who attributed this observation to that the presence 
of a large amount of this fatty acid could slow down the partitioning of the drug out of the gel base and skin, and hence result in the decrease in permeability rate of the drug. Furthermore, it was reported that $\mathrm{OA}$ is effective at relatively low concentrations typically less than $10 \%{ }^{30}$. The observable enhancing effect of menthol is in agreement with those reported by Liu et al., Kamal et al and Krishnaiah et al. ${ }^{31-33}$.

The ER of different gel formulation was listed in Table (3). The ERs of chitosan gel formulations were found to be 1.67, 1.33 and 5.13 for $F_{1}, F_{2}$ and $F_{3}$ respectively. For Carbopol 934p formulations $\mathrm{F}_{4}, \mathrm{~F}_{5}$ and $\mathrm{F}_{6}$, the ERs were 2.9, 1.27 and 2 respectively. The ERs were found to 2.14, 1.14 and 1.15 for HPMC formulations $\mathrm{F}_{7}, \mathrm{~F}_{8}$ and $\mathrm{F}_{9}$ respectively.

It was revealed that the chitosan formulation $\mathrm{F}_{3}$ has the highest ER among other formulations. It was reported that chitosan act as buccal penetration enhancer ${ }^{8}$. So that, the enhancing effect of menthol on the release of Mz may be potentiated by that of chitosan.

\section{Mz bioadhesive films}

The percent drug released of $\mathrm{Mz}$ from the prepared bioadhesive films were represented in Figure (5). It was found that the percent drug released were 5.65, 9.9, 20.34, 16.37 and 9.3\% for $\mathrm{F}_{\text {con } 4}, \mathrm{~F}_{10}, \mathrm{~F}_{\text {con } 5}, \mathrm{~F}_{11}$ and $\mathrm{F}_{12}$ respectively. It was revealed that the percent drug released from bioadhesive films was affected by the incorporation of penetration enhancer. Incorporation of 5\% OA with chitosan $\left(\mathrm{F}_{10}\right)$ result in increase in the percent $\mathrm{Mz}$ released when compared with that of chitosan only $\left(\mathrm{F}_{\text {con } 4}\right)$. The status was completely different for HPMC films. Oleic acid (5\%) $\left(\mathrm{F}_{12}\right)$ or menthol $(1 \%)\left(\mathrm{F}_{11}\right)$ incorporation led to decrease in the percent released of Mz less than that of HPMC only $\left(\mathrm{F}_{\text {con5 }}\right)$.

Table (3) shows the permeability coefficients and ER of the prepared films. It was observed that the permeability coefficients of chitosan based films were 0.36 and 0.54 $\left(\times 10^{-3} \mathrm{~g} / \mathrm{cm}^{2} . \mathrm{hr}\right)$ for formulations $\mathrm{F}_{\mathrm{con} 4}$ and $\mathrm{F}_{10}$ respectively. For HPMC based films $\mathrm{F}_{\text {con } 5}, \mathrm{~F}_{11}$ and $\mathrm{F}_{12}$ the permeability coefficients were 1.56 , 1.08 and $0.72\left(\times 10^{-3} \mathrm{~g} / \mathrm{cm}^{2} . \mathrm{hr}\right)$ respectively.

The ERs were 1.73, 0.821 and 0.454 for formulations $F_{10}, F_{11}$ and $F_{12}$ respectively. It was revealed that the incorporation of OA $(5 \%)$ and menthol $(1 \%)$ reduce amount permeated of
$\mathrm{Mz}$ for HPMC and on the other hand incorporation of OA (5\%) increase amount of $\mathrm{Mz}$ permeated from chitosan based film. It is obvious that chitosan based film containing 5\% $\mathrm{OA}\left(\mathrm{F}_{10}\right)$ has the highest ER.

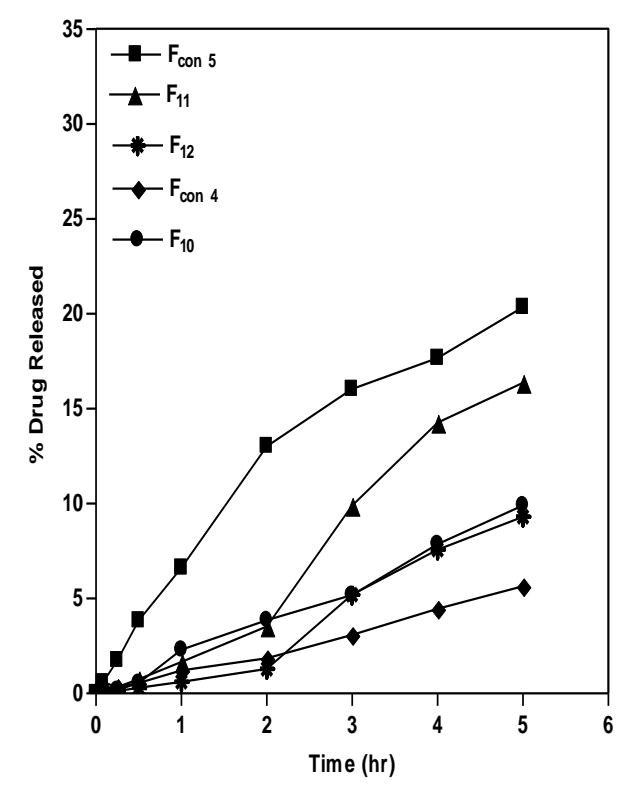

Fig. 5: Release profiles of $\mathrm{Mz}$ from chitosan $\left(\mathrm{F}_{10}\right)$ and $\operatorname{HPMC}\left(\mathrm{F}_{11}\right.$ and $\left.\mathrm{F}_{12}\right)$ based films.

Statistical analysis revealed that there are a statistically insignificant difference $(\mathrm{P}>0.05)$ between permeabilities of $F_{\text {con4 }}$ and $F_{10}$ and statistically significant difference $(\mathrm{P}<0.05)$ between permeabilities of $\mathrm{F}_{\text {con5 }}$ and $\left(\mathrm{F}_{11}, \mathrm{~F}_{12}\right)$.

These finding were in contrast to those reported in various studies. It was reported that oleic acid has been shown to enhance the permeation of a number of drugs such as insulin $^{34}$, amino $\operatorname{acids}^{35}$ and propranolol ${ }^{36}$ through oral mucosa. Also it was reported that menthol enhances permeation of morphine hydrochloride $^{37}$, imipramine hydrochloride ${ }^{38}$ and hydrocortisone ${ }^{15}$. It is well known that the enhancing effect of chemical enhancers could be dependent on the physicochemical properties of drugs and the combination with vehicle or ingredients in preparations ${ }^{39}$. Decrease in percent $\mathrm{Mz}$ permeated due to decrease in partition of enhancers into the ear rabbit skin was suggested to be a possible reason. The partition of penetration enhancers could also be dependent on the ratio of film formers, which can affect the affinity of enhancers to the film preparations ${ }^{40}$. 
The amount of $\mathrm{Mz}$ permeated still small due to the fact that, the diffusion through the rabbit skin is considered as multilayer diffusion process $^{41}$. Also presence of the complex and thick keratinised layer of rabbit ear skin, which early selected to mimic the nature of human gingiva, should be taken into account ${ }^{42}$.

\section{Surface pH and swelling behaviour of muco- adhesive films}

Surface $\mathrm{pH}$ evaluation of oral mucosal dosage forms is an important characterization study, as in-vivo studies by Bottenberg et al. ${ }^{43}$ demonstrated that an acidic or alkaline $\mathrm{pH}$ may cause irritation to the oral mucosa. It was therefore necessary to determine if any extreme surface $\mathrm{pH}$ changes occurred during the drug release period under investigation. The bioadhesive films with surface $\mathrm{pH}$ within the neutral conditions of the saliva, $\mathrm{pH}$ 5.8-7.1 throughout the test period are suitable for application $^{44}$.

Table (4) shows the surface $\mathrm{pH}$ of the prepared bioadhesive films. The surface $\mathrm{pH}$ values of the films were 5.33, 4.6, 6.37, 6.62 and 5 for $F_{\text {con4 } 4}, F_{10}, F_{\text {con5 }}, F_{11}$ and $F_{12}$ respectively. It was observed that the $\mathrm{pH}$ values of chitosan based films were lower than that of HPMC based film. This is in agreement with Amasya et $a l .{ }^{45}$ which attribute this reduction in $\mathrm{pH}$ to the incorporation of acid (acetic acid $(1.5 \%))$ as vehicle in chitosan films. Furthermore the incorporation of oleic acid (5\%) may result in further reduction of $\mathrm{pH}$ which may due to the acidic nature of oleic acid. So that, $F_{\text {con } 4}, F_{10}$ and $F_{12}$ may cause irritation to oral mucosa.

Table 4: Surface $\mathrm{pH}$ of the prepared $\mathrm{Mz}$ bioadhesive films.

\begin{tabular}{|c|c|}
\hline Formula code & $*$ Surface $\mathrm{pH}$ \\
\hline $\mathrm{F}_{\text {con4 }}$ & $5.33 \pm 0.169$ \\
\hline $\mathrm{F}_{10}$ & $4.6 \pm 0.101$ \\
\hline $\mathrm{F}_{\text {con5 }}$ & $6.37 \pm 0.147$ \\
\hline $\mathrm{F}_{11}$ & $6.62 \pm 0.288$ \\
\hline $\mathrm{F}_{12}$ & $5.00 \pm 0.179$ \\
\hline
\end{tabular}

*Mean of three determinations $\pm \mathrm{SD}$.

It was reported that the swelling properties of the formulations depend largely on the nature and amount of polymer present ${ }^{46}$.
Chitosan films undergo swelling over three hours to reach 15.83 and 11.46 followed by rapid erosion of the films to reach 14.5 and $8.33 \%$ for $F_{i}$ and $F_{i i}$ respectively. These results were in agreement with those of Nunthanid et $a l .{ }^{47}$ which reported that the swelling behavior of the polymeric blending with chitosan have a swelling index of $11.63 \%$. Also, Wenling et $a l .{ }^{48}$ reported that the chitosan films swelled greatly at the initial period and then decreased in volume with increased time.

The initial high percentage hydration was obtained for chitosan was attributed to its hydrophilic nature as a result of the presence of a free amino group in its structure. On the other hand the HPMC films show significant swelling without evident erosion over the whole period of experiment to reach 20.8, 25 and $15.6 \%$ after $4 \mathrm{hr}$ for $\mathrm{F}_{\text {con5 }}, \mathrm{F}_{11}$ and $\mathrm{F}_{12}$ respectively. This finding was in agreement with this mentioned by Cilurzo et al. ${ }^{49}$.

The effects of metronidazole formulations on the healing of experimentally induced periodontitis in guinea pigs

The time points were selected to capture critical periods during the three phases of the periodontal wound healing. It was reported that day three time points correspond to the peak of the inflammatory phase, the day fifteen time point corresponds to the peak in granulation tissue formation and the day thirty time point (one month) corresponds to the matrix formation phase ${ }^{50}$.

Figure (6) shows photomicrographic pictures of periodontal tissues of control group, $F_{10}$ treated group and $F_{3}$ treated group after three days respectively. In the control group formation of granulation tissue with marked blood vessel widening was observed. Osteoclastic activity, resorption of bone and marked tearing of periodontal ligament also were observed. It was found that three days after treatment with $\mathrm{F}_{3}$ there were presence of granulation tissue, resorption of bone and tearing of periodontal ligament that were less than that observed in the corresponding animals of control group.

Figure (7) shows photomicrographic pictures of periodontal tissues of control group, $F_{10}$ treated group and $F_{3}$ treated group after fifteen days respectively. It was found that in only some areas there are minimal granulation 


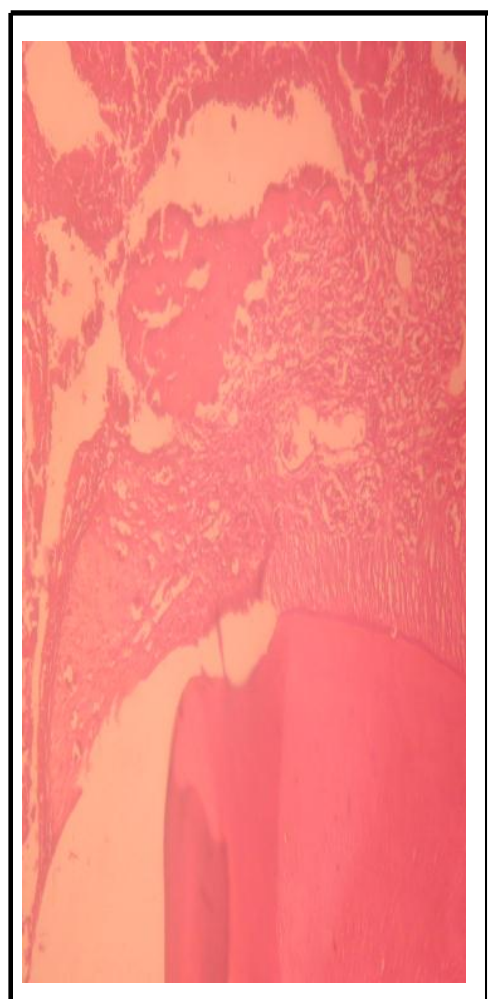

(A)

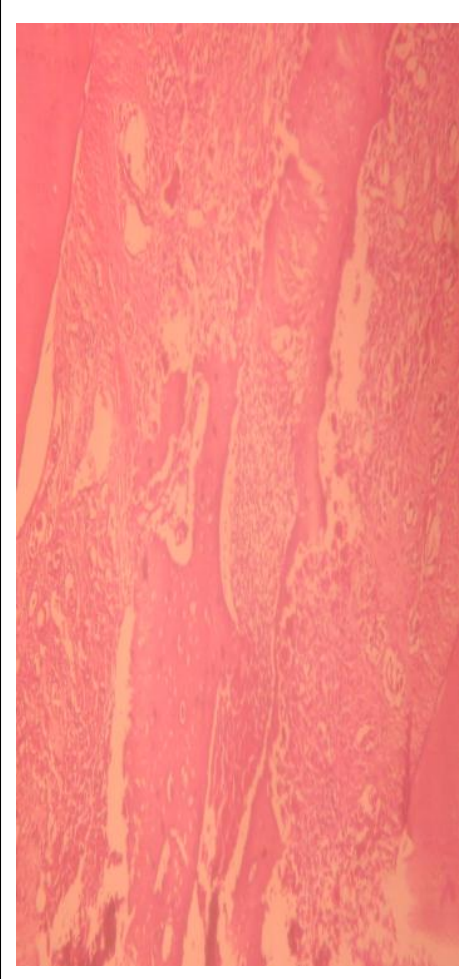

(B)

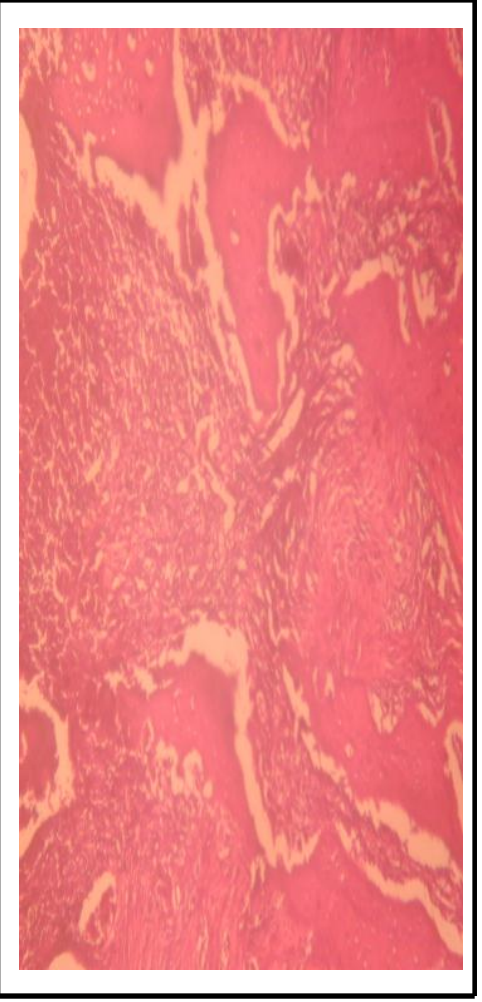

(C)

Fig 6: Photomicrographic pictures of periodontal tissues of control group (A), $\mathrm{F}_{10}$ treated group (B) and $\mathrm{F}_{3}$ treated group $(\mathrm{C})$ after three days.

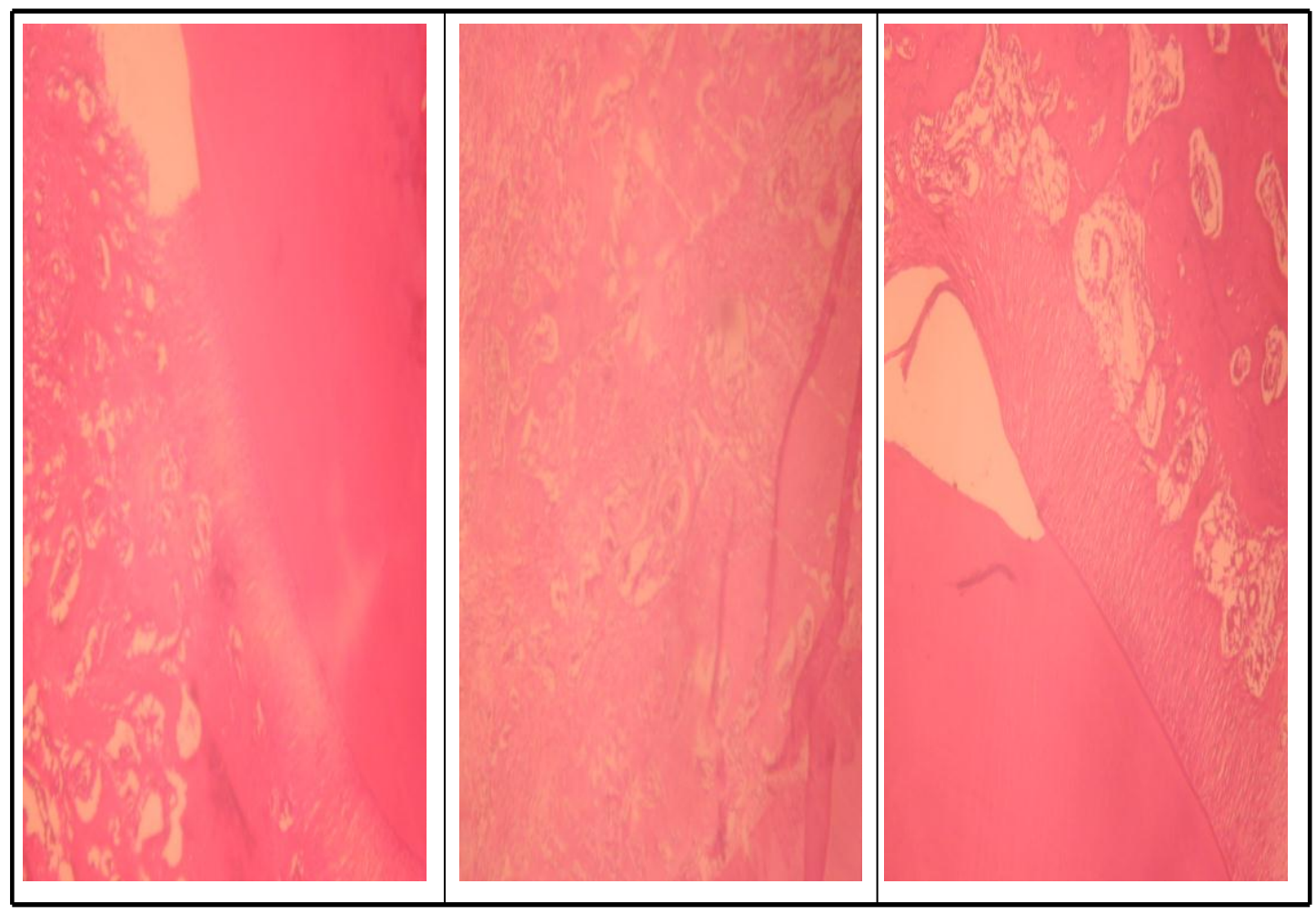

(D)

(E)

(F)

Fig 7: Photomicrographic pictures of periodontal tissues of control group (D), $\mathrm{F}_{10}$ treated group (E) and $F_{3}$ treated group $(F)$ after fifteen days. 
tissue, resorption of bone and tearing of periodontal ligament were still observed in the control group. After fifteen days of $F_{10}$ treatment, marked decrease in tearing of periodontal ligament fibers and bone resorption are observed. The observed periodontal ligament fibers organization is better than that of corresponding animals of control group but less than that of corresponding $\mathrm{F}_{3}$ treated animals.

Figure (8) shows photomicrographic pictures of periodontal tissues of control group, $F_{10}$ treated group and $F_{3}$ treated group after one month respectively. The followings were observed in the control group small areas of bone resorption, large areas of bone deposition and minimal tearing of periodontal ligament with some areas of disorganization. After one month treatment, good architecture of periodontal fibers and well bone formation were observed. Again, the observed periodontal fibers organization is better than that of corresponding animals of control group but less than that of corresponding $\mathrm{F}_{3}$ treated animals.

Table (5) shows the scoring system for comparing the healing of periodontium hard tissues in control and treated animals. For control group, it was found that the healing of the tissues was minimal three days after induction of periodontitis. Fifteen days after induction of periodontitis, the periodontal ligament organization and new alveolar bone formation improved while the reduction of granulation tissue still mild.

Further improvement was observed of periodontium to become improved but incomplete, nearly complete and improved but incomplete for the periodontal ligament organization, the reduction of granulation tissue and new alveolar bone formation respectively one month after induction of periodontitis.

For $\mathrm{F}_{3}$ treated group, it was found that the organization of periodontal ligament and formation of new alveolar bone were mild while the reduction of granulation tissue was moderate three days after treatment. Complete organization of periodontal ligaments was observed and the granulation tissue was completely disappeared fifteen days after treatment. Continual formation of new alveolar bone was observed to be nearly complete one month after treatment.

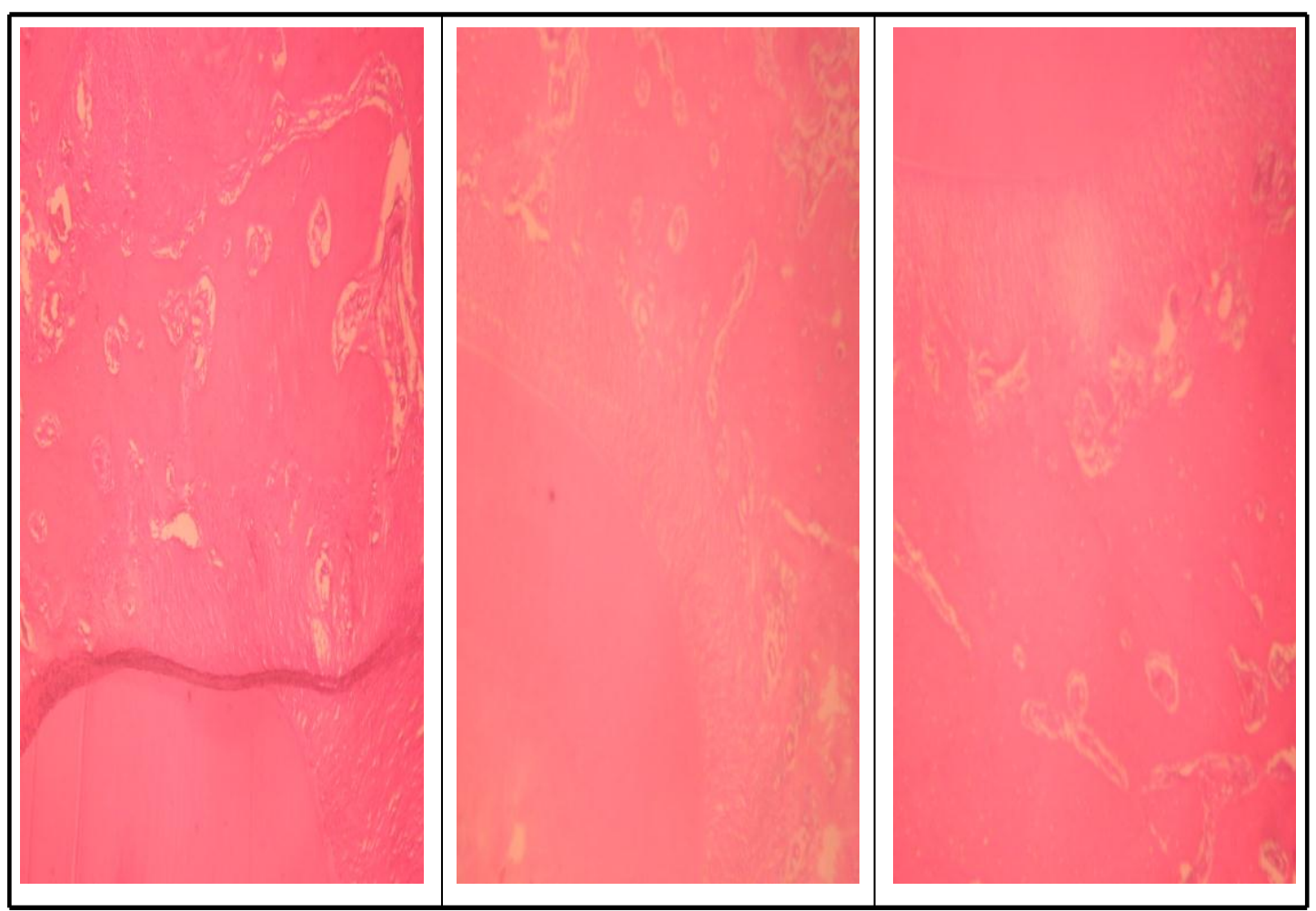

(G)
(H)
(I)

Fig 8: Photomicrographic pictures of periodontal tissues of control group $(\mathrm{G})$, F10 treated group $(\mathrm{H})$ and F3 treated group (I) after one month. 
Table 5: Scoring system of periodontium hard tissues healing in control and treated animals.

\begin{tabular}{|c|c|c|c|c|}
\hline Parameter & Test period & $\begin{array}{c}\text { Control } \\
\text { group }\end{array}$ & $\begin{array}{c}\mathrm{F}_{3} \text { treated } \\
\text { group }\end{array}$ & $\begin{array}{l}\mathrm{F}_{10} \text { treated } \\
\text { group }\end{array}$ \\
\hline \multirow{3}{*}{ 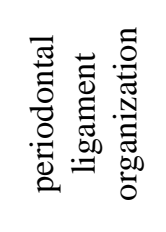 } & Three days & 0 & + & + \\
\hline & Fifteen days & ++ & ++++ & +++ \\
\hline & One month & +++ & ++++ & ++++ \\
\hline \multirow{3}{*}{ 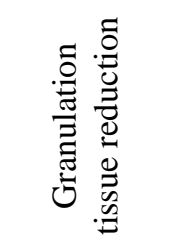 } & Three days & 0 & ++ & + \\
\hline & Fifteen days & + & ++++ & +++ \\
\hline & One month & ++++ & ++++ & +++ \\
\hline \multirow{3}{*}{ 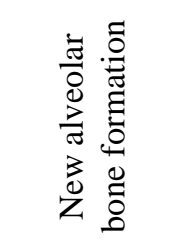 } & Three days & 0 & + & + \\
\hline & Fifteen days & ++ & +++ & +++ \\
\hline & One month & +++ & ++++ & +++ \\
\hline \multicolumn{2}{|c|}{ Sum } & 16 & 34 & 27 \\
\hline
\end{tabular}

For $\mathrm{F}_{10}$ treated group, it was found that the rate of healing was lower than $\mathrm{F}_{3}$ treated group. The healing of the tissues was observed to be mild three days after treatment. Further reduction of granulation tissue and formation of new bone were improved but incomplete at day fifteen of treatment without further improvement after one month of treatment. On the other hand, continual organization of periodontal ligament was observed to be complete one month after treatment respectively.

The sums of scores were 16, 34 and 27 for control group, $F_{3}$ and $F_{10}$ treated groups respectively. The differences in healing between treated groups and control group and between treated groups themselves were significant $(\mathrm{P}<0.05)$.

From the table it was concluded that the rate periodontium hard tissues healing of treated groups was more than that of control group. For groups treated with $\mathrm{Mz}$ bioadhesive formulations, the healing of the group treated with $F_{3}$ was higher than that of the other $F_{10}$ treated group.

The results of the present study revealed same sequence of bone healing in the test and control group but the osteoconductive new bone formation was more accelerated in the treated groups. For groups treated with $\mathrm{Mz}$ bioadhesive formulations, the healing of the group treated with $\mathrm{F}_{3}$ was higher than that of the other $\mathrm{F}_{10}$ treated group.

The obtained data were greatly in agreement to the nature of $\mathrm{Mz}$ where the healing observed in treated groups over control group may be attributed to the antibacterial activity of $\mathrm{Mz}$ against anaerobic gram-negative and gram-positive microorganisms ${ }^{51}$. In addition to Mz, chitosan was used as wound dressing without any drug to accelerate periodontal wound healing process ${ }^{52}$. Moreover, Needleman and Samles ${ }^{53}$ reported that chitosan showed extremely good wetting properties allowing remarkably close adaptation to tissue surface.

Although both formulations used for treatment containing the same concentration of $\mathrm{Mz}$ and chitosan, the healing efficacy was different. This could be originating from the difference in the dosage form or the nature of penetration enhancer used. The difference in healing may be due to that the bioadhesive force of chitosan film was less than that for 
chitosan bioadhesive gel plus the reduced water content of film less than gel. This would result in reduction in contact time and in turn reduction in treatment efficacy. Moreover, it was reported that gel as a dosage form is easily introduced into the periodontal pocket with a syringe which helps to ensure formulation retention within the pocket ${ }^{54}$.

The healing of group treated with bioadhesive gel containing menthol was higher than that for group treated with bioadhesive film containing oleic acid. This result was in agreement with a clinical study mentioned that menthol is more effective as penetration enhancer than oleic $\operatorname{acid}^{55}$. Furthermore, menthol exerts its effect via improvement in the partitioning of the drug into the tissues ${ }^{56}$. The reported cooling sensation of menthol is due to its vasodilator effect followed by analgesic effect $^{57}$. It was reported that oleic acid exerts its effect via lipid fluidization and lipid phase separation ${ }^{58}$, so that fatty acids need time to penetrate though skin and interact with lipid $^{59}$.

\section{Conclusion}

Treatment of periodontitis could be acclerated successfully by applications of local metronidazole delivery systems. The effects of bioadhesive gel containing 1\% menthol, 20\% metronidazole in $3 \%$ chitosan matrix on the healing of periodontal wound is greater than that of bioadhesive film containing $5 \%$ oleic acid, $20 \%$ metronidazole in $3 \%$ chitosan matrix.

\section{REFERENCES}

1- M. A. Listgartin, "Nature of periodontal disease: pathogenic mechanism", J. Priodontol. Res., 22, 172 (1987).

2- J. Slots and R. J. Genco, "Blackpigmented Bacteroides species, Capnocytophaga species and Actinobacillus actinomycetemcomitans in human periodontal disease: virulence factors in colonisation, survival and tissue destruction", J. Dental Res., 63, 412 (1984).

3- J. Lindhe and S. Nyman, "Long-term maintenance of patients treated for advanced periodontal disease", J. Clin. Periodontol., 11, 504 (1984).
4- N. J. Medlicott, "Delivery systems for the administration of the drugs to the periodontal pocket", Adv. Drug Deliv. Rev., 13, 181 (1994).

5- S. Yilmaz, B. Kuru, U. Noyan, T. Kadir, O. Acar and E. BuÈget, "A clinical and microbiological evaluation of systemic and local metronidazole delivery in early onset periodontitis patients", J. Marmara. Univ. Dent. Fac., 2, 500 (1996).

6- H. M. Kelly, P. B. Deasy, E. Ziaka and N. Claffey, "Formulation and preliminary invivo dog studies of a novel drug delivery system for the treatment of periodontitis", Int. J. Pharm., 274, 167 (2004).

7- J. Liebana, A. M. Castillo and M. Alvarez, "Periodontal diseases: microbiological considerations", Med. Oral Patol. Oral Cir. Bucal., 9, 82 (2004).

8- J. A. Nicolazzo, B. L. Reed and B. C. Finnin, "Buccal penetration enhancers: How do they really work?", J. Control. Release, 105, 1 (2005).

9- R. C. Rowe, P. J. Sheskey and P. J. Weller, eds., In "Handbook of Pharmaceutical Excipiets", $4^{\text {th }}$ Ed., Pharmaceutical Press and American Pharmaceutical Association, London, 2003, pp. 312, 383, 384, 390, 526.

10- S. Senel, G. Ikinci, S. Kas, A. YousefiRad, M. F. Sargon and A. A. Hincal, "Chitosan films and hydrogels of chlorhexidine gluconate for oral mucosal delivery", Int. J. Pharm., 193, 197 (2000).

11- F. Saker and Th. Borg, "Sonophoresis of clarithromycin for the treatment of skin infections: In-vitro and in-vivo evaluation in rabbit and human", Alex. J. Pharm. Sci., 14, 135 (2000).

12- N. A. Nafee, F. A. Ismail, N. A. Boraie and L. M. Mortada, "Mucoadhesive buccal patches of miconazole nitrate: Invitro/In-vivo performance and effect of ageing", Int. J. Pharm., 264, 1 (2003).

13- H. G. Choi, Y. K. Oh and C. K. Kim, "Insitu gelling and mucoadhesive liquid suppository containing acetaminophen: enhanced bioavailability", ibid., 165, 23 (1998).

14- H. S. Ch'ng, H. Park, P. Kelly and J. R. Robinson, "Bioadhesive polymers as platforms for oral controlled drug delivery, Part 2: Synthesis and evaluation 
of some swelling, water insoluble bioadhesive polymers", J. Pharm. Sci., 74, 399 (1985).

15- S. Nicoli, E. Penna, C. Padula, P. Colombo and P. Santi, "New transdermal bioadhesive film containing oxybutylin: In-vitro permeation across rabbit ear skin", Int. J. Pharm., 352, 2 (2006).

16- K. Yoneto, A. Ghanem, W. Higuchi, D. Peck and S. Kevin, Li. "Mechanistic studies of the 1-alkyl-2-pyrrolidones as skin permeation enhancers", J. Pharm. Sci., 84, 312 (1995).

17- A. F. El-Kattan, C. S. Asbill and B. B. Michniak, "The effect of terpene enhancer lipophilicity on the percutaneous permeation hydrocortisone formulated in HPLC gel systems", Int. J. Pharm., 198, 179, (2000).

18- N. A. Nafee, F. A. Ismail, N. A. Boraie and L. M. Mortada, "Mucoadhesive buccal patches of miconazole nitrate: $I n$ vitro/In-vivo performance and effect of ageing", ibid., 264, 1 (2003).

19- F. Sanavi, M. A. Listgarten, F. Boyd, K. Sallay and A. Nowotny, "The colonization and establishment of invading bacteria in periodontium of ligature-treated immunosuppressed rats", J. Periodontol., 56, 273 (1985).

20- L. M. Reis de Vasconcellos, L. H. Ricardo, I. Balducci, L. G. Oliveira de Vasconcellos and Y. K. Carvaiho, "Histological analysis of the effects of 24\% EDTA gel for nonsurgical treatment of periodontal tissues", J. Oral Sci., 48, 207 (2006).

21- R. A. Druy and E. A. Wallington, Eeds., "Carletons Histological Techniques", $5^{\text {th }}$ Ed., Oxford, New York, Toronto, 1980, pp. 303-350.

22- J. Schulz and M. Nardin, "Theories and Mechanism of Adhesion" In: "Handbook of Adhesive Technology" Pizzi, A. and Mittal, K.L., eds., Marcel Dekker, New York, 1994, pp. 19-34.

23- J. M. Gu, J. R. Robinson and S. H. S. Leung, "Binding of acrylic polymers to mucin/epithelial surfaces: structureproperty relationships", Crit. Rev. Ther. Drug Carr. Syst., 5, 21 (1998).

24- N. A. Peppas and P. A. Buri, "Surface, interfacial and molecular aspects of polymer bioadhesion on soft tissues", J. Control. Release, 2, 257 (1985).

25- A. K. Singla, M. Chawla and A. Singh, "Potential applications of carbomer in oral mucoadhesive controlled drug delivery system: a review", Drug Dev. Ind. Pharm., 26, 913 (2000).

26- C. M. Lehr, J. A. Bouwstra, E. H. Schacht and H. E. Junginger, "In-vitro evaluation of mucoadhesive properties of chitosan and some other natural polymers", Int. J. Pharm., 78, 43 (1992).

27- C. F. Wong, K. H. Yuen and K. K. Peh, "An in-vitro method for buccal adhesion study: Importance of instrument variables", ibid., 180, 47 (1999).

28- H. G. Choi and C. K. Kim, "Development of omeprazole buccal adhesive tablets with stability enhancement in human saliva", J. Control. Rel., 68, 397 (2000).

29- S. A. Mortazavi and R. Aboofazeli, "An investigation into the effect of various penetration enhancers on percutaneous absorption of piroxicam", IJPR, 2, 135 (2003)

30- A. C. Williams and B. W. Barry, "Penetration enhancers", Adv. Drug. Deliv. Rev., 56, 603 (2004).

31- Y. Liu, Y. Xun, F. Xuemei, Z. Guanhuai, R. Zhengxing, F. Chao, F. and C. Hongzhuan, "Menthol facilitates the skin analgesic effect of tetracaine gel", Int. J. Pharm., 305, 31 (2005).

32- M. Kamal, N. Iimura, T. Nabekura and Sh. Kitagawa, "Enhanced skin permeation of salicylate by ion-pair formation in nonaqueous vehicle and further enhancement by ethanol and l-menthol", Chem. Pharm. Bull., 54, 481 (2006).

33- Y. S. Krishnaiah, M. S. Kumar, V. Raju, M. Lakshmi and B. Rama, "Penetrationenhancing effect of ethanolic solution of menthol on transdermal permeation of ondansetron hydrochloride across rat epidermis", Drug Deliv., 15, 227 (2008).

34- M. Morishita, J. M. Barichello, K. Takayama, Y. Chiba, S. Tokiwa and T. Nagai, "Pluronic RF-127 gels incorporating highly purified unsaturated fatty acids for buccal delivery of insulin", Int. J. Pharm., 212, 289 (2001).

35- J. W. Lee, J. H. Park and J. R. Robinson, "Bioadhesive-based dosage form: the next 
generation", J. Pharm. Sci., 89, 850 (2000).

36- A. M. Manganaro and P. W. Wertz, "The effects of permeabilizers on the in-vitro penetration of propranolol through porcine buccal epithelium", Mil. Med., 161, 669 (1996).

37- H. Morimoto, Y. Wada T. Seki and K. Sugibayashi, "In-vitro skin permeation of morphine hydrochloride during the finite application of penetration enhancing system containing water, ethanol and Lmenthol", Biol. Pharm. Bull., 25, 134 (2002).

38- A. K. Jain, N. S. Thomas and R. Panchagnula, "Transdermal drug delivery of imipramine hydrochloride: I. Effect of terpenes", J. Control. Release, 79, 93 (2002).

39- K. Higaki, C. Amnuaikit and T. Kimura, "Strategies for overcoming the stratum corneum: chemical and physical approaches", Am. J. Drug Deliv., 1, 187 (2003).

40- H. A. Cheong and H. K. Choi, "Effect of ethanolamine salts and enhancers on the percutaneous absorption of piroxicam from a pressure sensitive adhesive matrix", Eur. J. Pharm. Sci., 18, 149 (2003).

41- A. Martin, P. Bustamante and A. H. C. Chun, "Kinetics and Drug Stability", Chapter 12, In: "Physical Pharmacy", $4^{\text {th }}$ Ed., lea and Febiger, Philadelphia, U.S.A., 1993, pp. 284-323.

42- A. Ganem-Quintanar, Y. M. Kalia, F. Falson-Rieg and P. Buri, "Mechanisms of oral permeation enhancement", Int. J. Pharm., 156, 127 (1997).

43- P. Bottenberg, R. Cleymaet, C. D. Muynck, J. Renon, D. Coomans and Y. Slop, "Development and testing of bioadhesive, fluoride-containing slow release tablets for oral use", J. Pharm. Pharmacol., 43, 457 (1991).

44- V. A. Perumal, D. Lutchman, I. Mackraj and T. Govender, "Formulation of monolayered films with drug and polymers of opposing solubilities", Int. J. Pharm., 358, 184 (2008).

45- G. Amasya, S. Y. Karavana, T. Şen, E. Baloğlu and N. Tarımc1, "A Comparision of Mechanical Properties of Buccal Gel
Formulations Based on Different Bioadhesive Polymers" In: " $3^{\text {rd }}$ BBBB International Conference of Pharmaceutical Science", A. A. Hincal, N. Celebi and N. Yuksel, eds., AntalyaTurkey, 2009, pp. 105-106.

46- J. S. Boateng, K. H. Matthews, A. D. Auffret, M. J. Humphrey, H. N. Stevens and J. N. Eccleston, "In-vitro drug release studies of polymeric freeze-dried wafers and solvent-cast films using paracetamol as a model soluble drug", Int. J. Pharm., 378, 66 (2009).

47- J. Nunthanid, S. Puttipipatkhachorn, K. Yamamoto and G. E. Peck, "Physical properties and molecular behaviour of chitosan films", Drug Dev. Ind. Pharm., 27, 143 (2001).

48- C. Wenling, J. Duohui, L. Jiamou, G. Yandao, Z. Nanming and Z. Xiufang, "Effects of the degree of deacetylation on the physicochemical properties and Schwann cell affinity of chitosan films", J. Biomater. Appl., 20, 157 (2005).

49- F. Cilurzo, P. Minghetti, F. Selmin, A. Casiraghi and L. Montanari, "Polymethacrylate salts as new lowswellable mucoadhesive Materials", J. Control. Rel., 88, 43 (2003).

50- X. Zhang, M. Kohli, Q. Zhou, D. T. Graves and S. Amar, "Short and long term effects of IL-1 and TNF antagonists on periodontal wound healing", J. Immunol., 173, 3514 (2004).

51- R. A. Seymour and P. A. Heasman, "Pharmacological control of periodontal disease: II. Antimicrobial agents", J. Dent., 23, 5 (1995).

52- S. Minami, Y. Okamoto, A. Matuhashi, Y. Shigemasa, T. Tanya, Y. Tanaka and Tokyra, "Fibroblast Formation by Regenerated Chitin Derivative" In: "Chitin Derivative in Life Science", S. Tokura and I. Azuma, eds., International Symposium Ion Chitin Derivative in Life Sciences, 1992, pp. 68-76.

53- I. G. Needleman and F. C. Smales, "Invitro assessment of bioadhesion for periodontal and buccal drug delivery", Biomaterials, 16, 617 (1995).

54- G. Ikinci, S. Senel, H. Akıncıbay, S. Kas, S. Ercis, C. G. Wilson and A. A. Hincal, "Effect of chitosan on a periodontal 
pathogen Porphyromonas gingivalis", Int. J. Pharm., 235, 121 (2002).

55- I. I. Abu Hashim, "Pharmaceutical Studies on the Effect of Certain Enhancers on Some Drug Delivery Systems", M.Sc Thesis, Faculty of Pharmacy, Mansoura University, Egypt (2005).

56- S. Gao and J. Singh, "In-vitro percutaneous absorption enhancement of lipophilic drug tamoxifen by terpenes", J. Control. Rel., 51, 193 (1998).

57- Martindale, "The Complete Drug Reference", K. Parfitt, ed., $32^{\text {th }}$ Ed., The Pharmaceutical Press Lambeth Street, London, UK, 1999, pp. 772, 1600.
58- A. Naik, L. A. R. M. Pechtold, R. O. Potts and R. H. Guy, "Mechanism of oleic acid induced skin penetration enhancement invivo in humans", J. Control. Release, 37, 299 (1995).

59- S. Santoyo, A. Arellano, P. Ygartua and C. Matrin, "Penetrion enhancer effects on the in-vitro percutaneous absorption of piroxicam through rat skin", Int. J. Pharm., 117, 219 (1995). 